\title{
Facts about Chromium ${ }^{1}$
}

Linda B. Bobroff ${ }^{2}$

\section{Why do we need chromium?\#}

Chromium is one of the trace minerals. This means that it's found in very small amounts in our bodies. Chromium works with insulin to maintain normal blood glucose levels.

Chromium helps us use the carbohydrate and fat from our diets. It also can affect the amount of fat and protein in our bodies. Many athletes are interested in chromium for this reason.

\section{What happens if we don't get enough chromium?}

The effects of a chromium deficiency in healthy people are not well known. Lack of

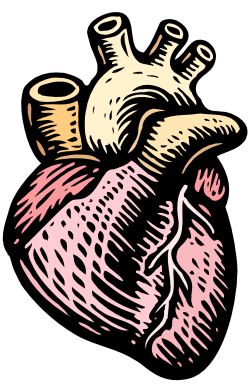
chromium may affect glucose uptake into cells. It also may cause blood lipids to rise, which could increase risk for heart disease.

\section{How much chromium do we need?}

The following table lists recommended daily intakes of chromium. Many people get less chromium than this, but scientists aren't sure whether or not this represents a health risk. Chromium needs may decrease with age, but more research needs to be done with older people to confirm this theory.

\begin{tabular}{||l|c||}
\hline \multicolumn{1}{|c|}{ Life Stage } & $\begin{array}{c}\text { Amount } \\
\text { (mcg/day) }\end{array}$ \\
\hline \hline Men, ages 19-50 & 35 \\
\hline Women, ages 19-50 & 25 \\
\hline Men, ages 51+ & 30 \\
\hline Women, ages 51+ & 20 \\
\hline \begin{tabular}{l} 
Pregnancy, ages 19-50* \\
\hline Lactation, ages 19-50*
\end{tabular} \\
\hline \hline $\begin{array}{l}\text { mcg = micrograms of chromium } \\
\star \\
\text { (Pregnant or lactating 14-18 year olds need } \\
1 \text { mcg per day LESS than those 19-50 years of } \\
\text { age. }\end{array}$ \\
\hline
\end{tabular}

1. This document is FCS8803, one of a series of the Department of Family, Youth and Community Sciences, Florida Cooperative Extension Service, Institute of Food and Agricultural Sciences, University of Florida. Publication date: December 2006. Please visit the EDIS Web site at http://edis.ifas.ufl.edu.

2. Linda B. Bobroff, PhD, RD, LD/N, professor, Department of Family, Youth and Community Sciences, Cooperative Extension Service, Institute of Food and Agricultural Sciences, University of Florida, Gainesville, FL 32611. 


\section{How can we get enough chromium?}

Both animal and plant foods contain chromium, but exact amounts have not been determined partly because the amount of chromium varies a lot depending on soil types and other factors.

Animal foods contain only small amounts of this trace mineral. Good food sources include

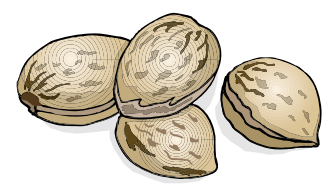
mushrooms, prunes, asparagus, nuts, whole

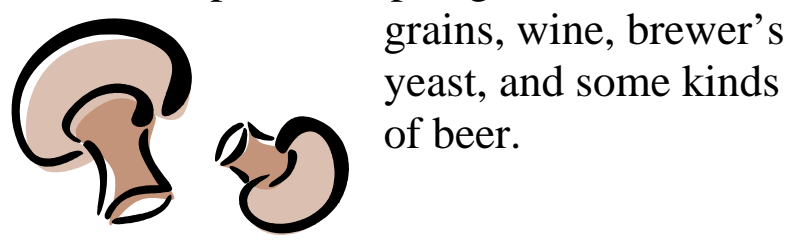

Chromium is a component of steel. So when you cook acidic foods like tomato sauce in stainless steel pots, it adds small amounts of chromium to the food.

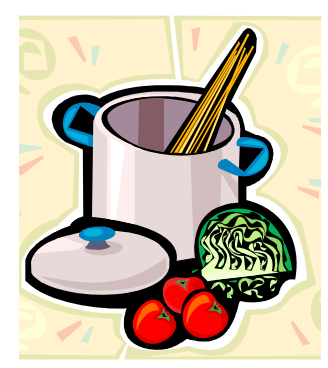

\section{What about supplements?}

Some athletes take chromium supplements to enhance performance. There is only limited information about the value of chromium for this purpose.

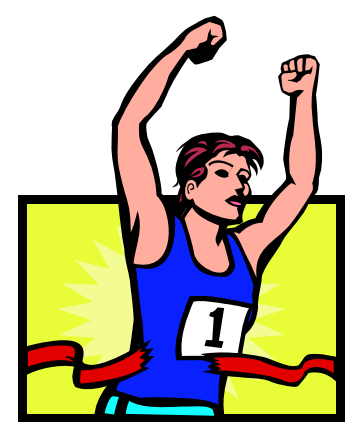

Because of its role in glucose use in the body, persons with diabetes may have an interest in chromium. Most persons with diabetes are not chromium deficient and do not need supplements.
The American Diabetes Association currently does not recommend chromium supplements for persons with diabetes.

One popular form of chromium supplement is chromium picolinate. This form of chromium has been found to cause DNA damage in cell culture studies. Until further studies are done, it would be wise to avoid chromium picolinate. Excessive chromium intake has also been linked to kidney failure.

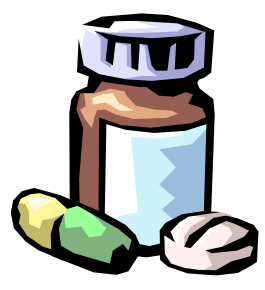

\section{How much is too much?}

Chromium is absorbed very poorly. It would take a high dose of this mineral to cause a toxic reaction. You cannot get too much chromium from food sources. No upper limit of chromium in the diet has been set. Of course, it is always wise to avoid large doses of any nutrient in supplement form.

\section{Where can I get more information?}

The Family and Consumer Sciences (FCS) agent at your county Extension office may have more written information and nutrition classes for you to attend. Also, a registered dietitian (RD) can provide reliable information.

Reliable nutrition information may be found on the Internet at the following sites:

http://fycs.ifas.ufl.edu http://solutionsforyourlife.org http://www.nal.usda.gov/fnic http://www.nutrition.gov http://www.diabetes.org 